\title{
Mini Two-port Laparoscopic Appendicectomy with Novel Knotting Technique
}

\author{
Jitendra T Sankpal ${ }^{1}$, Mukund B Tayade ${ }^{2}$, Ajay H Bhandarwar ${ }^{3}$, Priyanka Saha ${ }^{4}$, Soumya Chatnalkar ${ }^{5}$, Sushrut Sankpal ${ }^{6}$,
} Ameya Gadkari ${ }^{7}$

\begin{abstract}
Background: In pursuit of minimizing surgical trauma and achieving better esthetics by reducing the size and number of ports, this mini two-port technique was devised to offer an easier and safe alternative in comparison to conventional three-port technique. An easy and costeffective mini two-port appendicectomy is made possible with a unique intracorporeal surgical knotting through a single 5-mm port with a single instrument, thus reducing number and size of ports and with a better cosmetic result.

Materials and methods: Total 200 patients underwent laparoscopic appendicectomy out of which, mini two-port appendicectomy (TPA) with novel knotting technique could be successfully performed on 168 patients $(84 \%)$ and remaining 32 patients (16\%) required conventional threeport technique (CLA). None of the cases were converted to open.

Results: Patient undergoing two-port laparoscopic appendicectomy had shorter operative time with better cosmetic result with no incidence of port-site hernia. There was no difficulty in adhesiolysis and intraoperative bleeding control. Infection rate was $0.59 \%$ and $3.12 \%$ for TPA and CLA, respectively. Incidence of intraoperative bleeding and intraoperative rupture of appendix was less in TPA (1.19\% and 0\%) as compared to CLA (6.25\% and 3.125\%). Mean hospital stay was less in TPA (1.7 days) compared to CLA (2.1 days).

Conclusion: This mini two-port technique with novel knotting technique is easy to learn and helps to overcome the challenges and limitations faced during two laparoscopic appendicectomies; however conversion to conventional approach in complicated cases is still advisable. It is safe and effective intermediate option from conventional three-port to SILS/NOTES/Endo GIA staplers.

Keywords: Appendicitis, Laparoscopic appendicectomy, Novel knotting technique, Two-port laparoscopic appendicectomy. World Journal of Laparoscopic Surgery (2020): 10.5005/jp-journals-10033-1398
\end{abstract}

\section{INTRODUCTION}

Acute appendicitis is common gastrointestinal condition in emergency surgical practice. It affects group of people irrespective of age, nationality, and religion. The incidence of acute appendicitis is probably lower in Asian and African countries accounting to the intake of high fiber diet by their inhabitants. Dietary fiber helps decrease the viscosity of feces, decrease bowel transit time, and reduce the formation of fecolith, one of the common causes of appendiceal lumen obstruction.

In an age group of 21-30 years, highest incidence is seen in male compared to female, where the highest incidence was observed in the age group of 11-20 years. Incidence remains same for both sexes after the age of 30 years.

The diagnosis is done by clinical signs and symptoms, Mantrels score, ultrasonography, computerized tomography. Computerized tomography being the investigation of choice. The treatment of modality for appendicitis is appendicectomy. Laparoscopy is a new gold standard for treatment of acute and chronic appendicitis. Conventional appendicectomy is by 3-port technique. But in pursuit of minimizing surgical trauma and achieving better cosmetic results without compromising on basic principal of appendicectomy, this mini two-port technique is described, wherein limitations and challenges of intracorporeal knotting faced during two-port technique by using single $5-\mathrm{mm}$ port are overcome by our novel knotting technique, thus to make mini two-port technique feasible. This technique can be considered as safe, cosmetic, and cost-effective intermediate option between three-port technique and Stapler, SILS, NOTES appendicectomy.

\footnotetext{
1,2Department of General and Laparoscopic Surgery, Gokuldas Tejpal Hospital of Grant Government Medical College and Sir JJ Government Hospitals, Mumbai, Maharashtra, India

3-5,7 Department of General Surgery, Grant Government Medical College and Sir JJ Hospital, Mumbai, Maharashtra, India

${ }^{6}$ Department of General and Laparoscopic Surgery, Rajiv Gandhi Medical College, Kalwa, Thane, Maharashtra, India

Corresponding Author: Jitendra T Sankpal, Department of General and Laparoscopic Surgery, Gokuldas Tejpal Hospital of Grant Government Medical College and Sir JJ Government Hospitals, Mumbai, Maharashtra, India, Phone: +91 9920527799, e-mail: drjts_ palmbeach@yahoo.co.in

How to cite this article: Sankpal JT, Tayade MB, Bhandarwar AH, et al. Mini Two-port Laparoscopic Appendicectomy with Novel Knotting Technique. World J Lap Surg 2020;13(1):21-25.

Source of support: Nil

Conflict of interest: None
}

\section{Materials and Methods}

A total of 200 prospective nonrandomized patients were subjected to begin with two-port laparoscopic appendicectomy over the period of 3 years from 2014 to 2016 for appendicitis after written, informed, and valid consent. Ethical clearance was not obtained since it was a study involving variation in knotting technique. Of these, in 168 patients, mini two-port appendicectomy (TPA) was feasible, and in remaining 32 patients, conventional laparoscopic appendicectomy (CLA) had to be done due to severe inflammation, adhesions, and specimen that cannot be retrieved through 5-mm

() The Author(s). 2020 Open Access This article is distributed under the terms of the Creative Commons Attribution 4.0 International License (https://creativecommons. org/licenses/by-nc/4.0/), which permits unrestricted use, distribution, and non-commercial reproduction in any medium, provided you give appropriate credit to the original author(s) and the source, provide a link to the Creative Commons license, and indicate if changes were made. The Creative Commons Public Domain Dedication waiver (http://creativecommons.org/publicdomain/zero/1.0/) applies to the data made available in this article, unless otherwise stated. 
port. Young cosmesis oriented patients with acute appendicitis without lump or perforation, recurrent appendicitis having symptoms due to fecolith, and incidental finding of inflamed appendix in diagnostic laparoscopy. Preileal, subceacal, and pelvic position of appendix were preferred.

\section{Operative Technique}

Under general anesthesia, patient is placed in Trendelenburg position with laparoscopy trolley on patient's right and surgeon on patient's left side. Laparoscopic access into the abdomen was obtained via Hasson's technique through the umbilicus with $5-\mathrm{mm}$ port, and the procedure was started by creating pneumoperitoneum through umbilical port with insufflation pressures being maintained between 10 and $12 \mathrm{~mm} \mathrm{Hg}$. A $5-\mathrm{mm} 30^{\circ}$ scope is introduced through the 5-mm umbilical port. Under direct vision, a 5-mm trocar was inserted through a suprapubic incision made below the pubic hairline (Fig. 1). A 2-0 polypropylene suture is threaded and reversed through an 18-gauge epidural needle to create a loop at the tip. This needle loop retractor is then inserted in the right iliac fossa (Fig. 1) at the position of appendix as defined by laparoscopy. Dissection of mesoappendix up to the base of the mesoappendix is done using bipolar energy device (Fig. 1).

\section{In Case of Dense Adhesions and When Tip of Appendix is Not Visualized}

In difficult appendix with adhesions and when the tip of the appendix is not visualized, a double loop retraction, one with additional subserosal appendix stitch with 2-0 polyglactin suture passed through abdominal wall is taken on most visible portion of appendix which aides in retraction and dissection of the appendix, and when tip becomes visible, a second 2-0 polypropylene loop retraction as described above is used (Fig. 1) to hitch up the appendix and aid in the process of adhesiolysis (Fig. 1). After adequate mobilization, first polyglactin suture is later removed

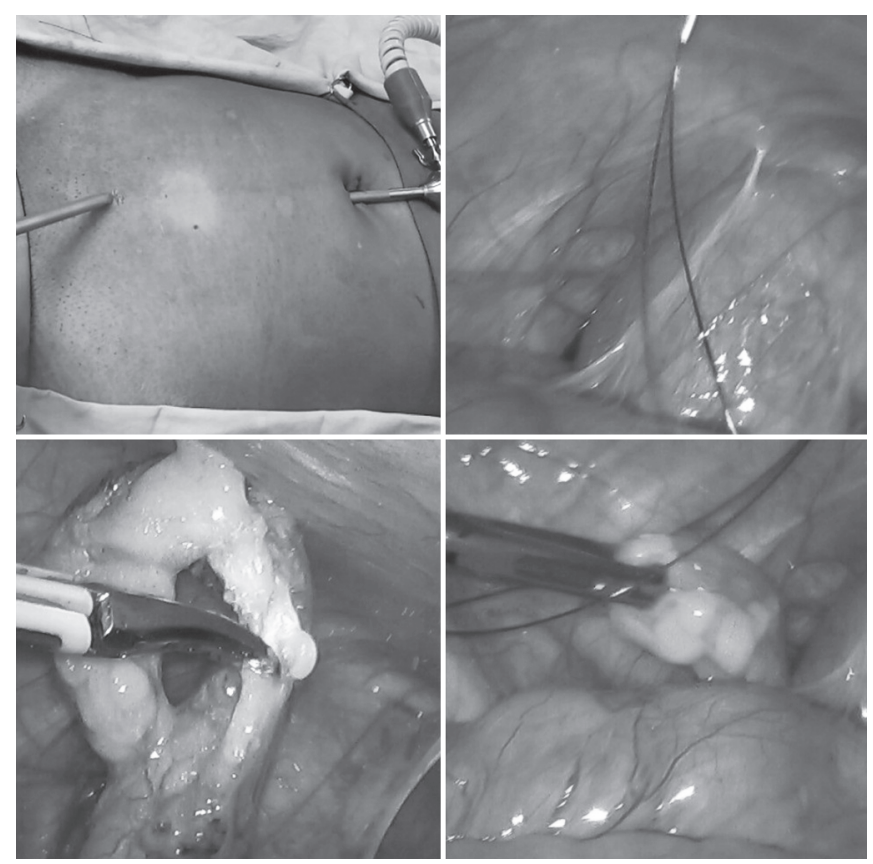

Fig. 1: Two 5-mm port placement, polypropylene loop retraction of appendix, and dissection of mesoappendix with bipolar device up to base of appendix and then the tip of appendix is then repositioned within 2-0 polypropylene loop. Mesoappendix is divided with bipolar energy device till base is visible (Fig. 1). A segment of 2-0 polyglactin suture held on tip of needle holder together is introduced through the 5-mm suprapubic port so as to encircle the base of the appendix. After encircling the base and creating a loop, tip of the 2-0 polyglactin suture is again held with needle holder in the right hand of surgeon and with outer end of 2-0 polyglactin suture held in surgeon's left hand, and single instrument surgical knot analogs to the open technique is performed (Fig. 2), wherein internal end of the suture is held with needle holder in the right hand and the long end of 2-0 polyglactin suture is held externally by the left hand. Another knot is placed at the distal location in the similar fashion and appendix is divided and delivered through either of $5-\mathrm{mm}$ port after completely withdrawing specimen within the cannula of 5-mm port to prevent port-site contamination.

\section{In a Case of Grossly Inflamed Appendix/Edematous Cecum}

In an instance of the edematous cecum and grossly inflamed appendix, base of the appendix is transfixed (Fig. 3) with entire length of 2-0 polyglactin suture introduced through a percutaneous puncture in right iliac fossa, needle is cut and retrieved through right iliac fossa, and opposite long end of suture is pulled out through 5-mm port alongside of the needle holder. Knot analogous to the open surgical knot is placed as described above, and then second surgical intracorporeal knot is placed distally. Appendix is divided between two knots and retrieved. None of the operated cases were converted to conventional 3-port or open appendicectomy.

\section{Results}

A total of 200 patients were operated of which 168 underwent TPA and 32 underwent CLA. Comparison of the two group's operative time was 24 minutes and 42 minutes for TPA and CLA, respectively.
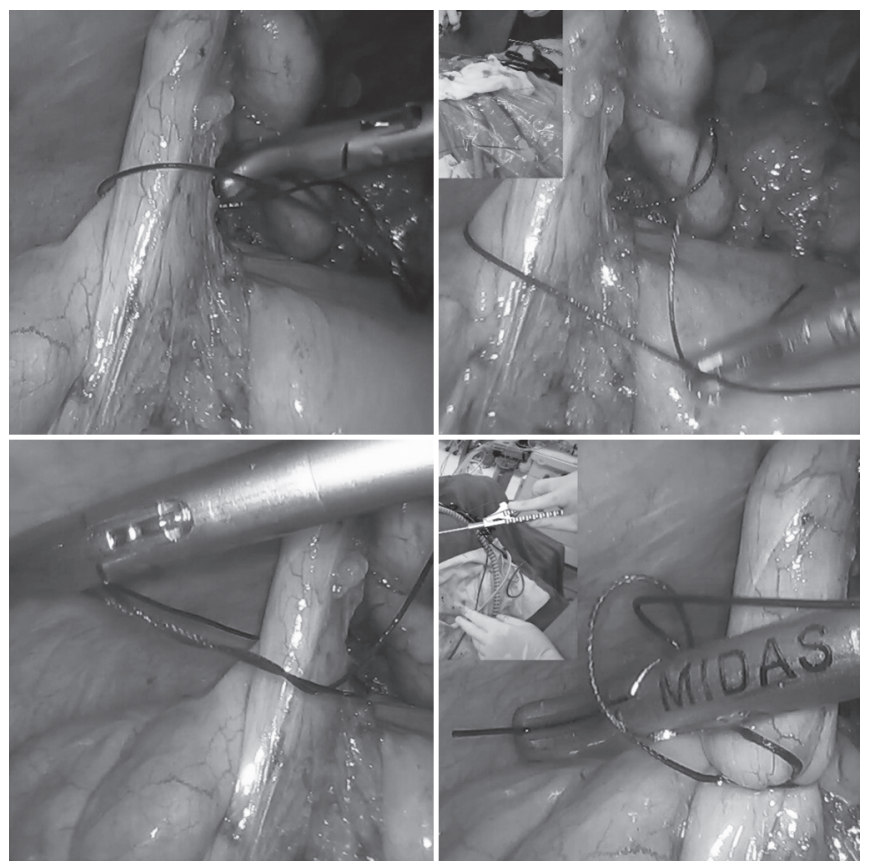

Fig. 2: 2-0 Polyglactin held with needle holder is passed through 5-mm port; suture is encircled around the base to form loop, and surgical knot tied 
Better cosmesis achieved in TPA as scar was hidden in umbilicus and pubic hairline producing scarless appearance (Fig. 4) and scar was visible at umbilicus and left iliac fossa in CLA. Infection rate was $0.59 \%$ and $3.125 \%$ for TPA and CLA, respectively. Incidence of intraoperative bleeding and intraoperative rupture of appendix was less in TPA (1.19\% and 0\%, respectively) as compared to CLA (6.25\% and $3.125 \%$, respectively). Mean hospital stay was less in TPA (1.7 days) compared to CLA (2.1 days). No major intraoperative complications were observed (Table 1).

\section{Discussion}

The incidence of appendicitis gradually rises from birth, ${ }^{1}$ peaks in the late 10 years, and gradually declines in the geriatric years. ${ }^{2}$ It is most prevalent in young belonging to the age group of 10-19 years. ${ }^{3}$ In recent years, the number of cases in patients aged 30-69 years has increased to $6.3 \% .{ }^{4}$ However, cosmesis has been an utmost importance lately among all the age groups.

Clinical presentation of $30 \%$ to $45 \%$ patients suspected of appendicitis is frequently unspecified and despite common
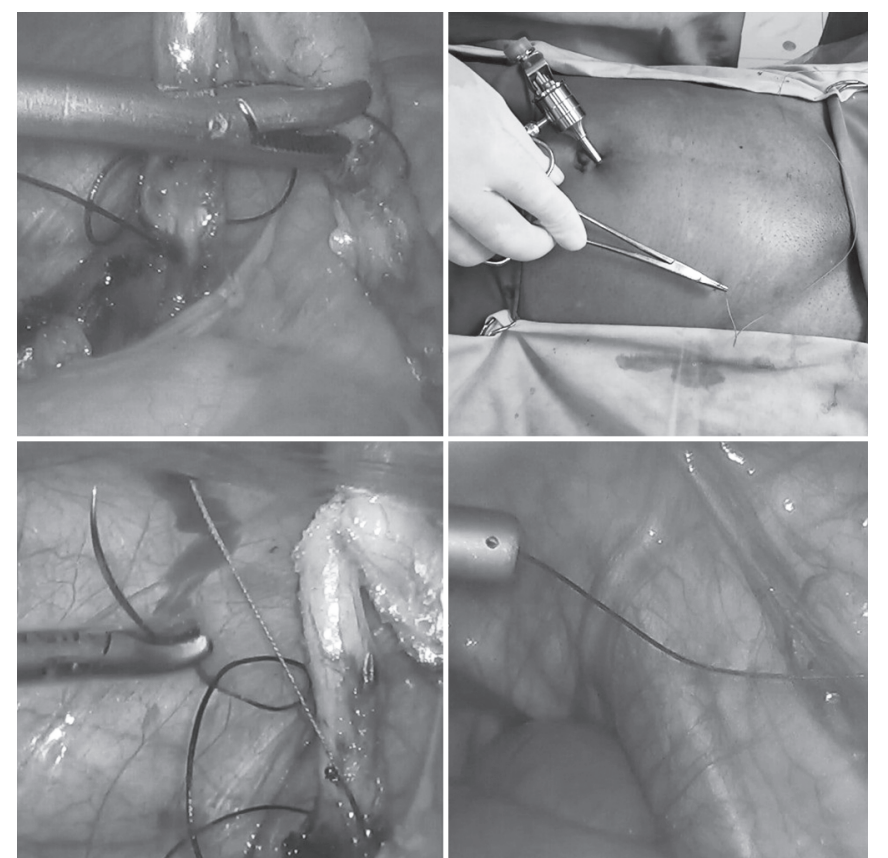

Fig. 3: Trans-fixation of base of appendix by percutaneous introduction of polyglactin suture, needle retrieved, and long end of suture pulled out through port and knotting done occurrence leads to many difficulties in diagnosis. Diagnosis of acute appendicitis includes clinical examination, laboratory tests, diagnostic scoring systems, and imaging modalities like ultrasonography and computerized tomography. CT demonstrates a sensitivity and specificity of $83 \%-100 \% .^{5}$ Scoring systems link clinical examination and laboratory tests by certain quantification of symptoms, signs, and laboratory parameters. ${ }^{6}$

The first successful appendicectomy was performed in by Claudius Amyand in 1735. Laparoscopic appendicectomy was first performed by the German gynecologist Kurt Semm in $1980,{ }^{7}$ which became a new gold standard in surgical treatment of appendicitis. ${ }^{8}$ Surgical advancement in the management of acute appendicitis has evolved in great extent in the last 120 years, from McBurney's simple large incision and its modification to minimally invasive LA, to barely noticeable incisions after single-incision laparoscopic surgery (SILS). ${ }^{9}$

The safest treatment in all stages of the inflamed appendix is appendicectomy. ${ }^{10}$ Open appendicectomy always results in a disfiguring scar over the abdomen. Cosmetic outcome is important to consider as the disease affects mainly the young people. ${ }^{11,12}$ Apart from cosmesis, Larson et al. ${ }^{13}$ has established numerous reasons why a laparoscopic procedure stands superior to the conventional open appendicectomy which includes better visualization and magnification, exploration of all surrounding viscera, better handling in obese patients, minimal tissue trauma, and reduced the incidence of surgical-site infection. ${ }^{14,15}$

The conventional three-port laparoscopic appendicectomy includes $10-\mathrm{mm}$ camera port at the umbilicus and 2 working $5-\mathrm{mm}$
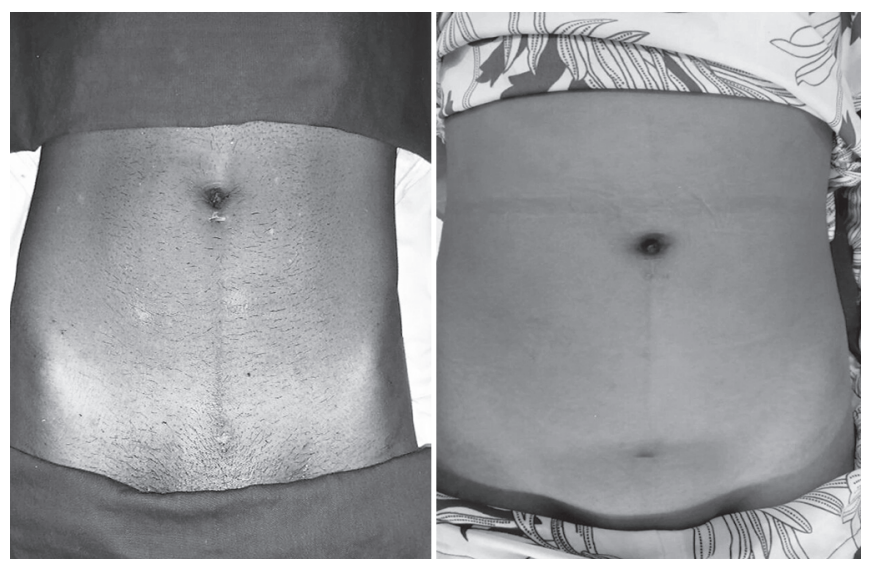

Fig. 4: Postoperative scar in male and female patients

Table 1: Showing results of two-port appendicectomy vs conventional laparoscopic appendicectomy

\begin{tabular}{|c|c|c|c|}
\hline S. no & Parameters & $\begin{array}{l}\text { Mini two-port technique of appendicectomy } \\
(n=168)\end{array}$ & $\begin{array}{l}\text { Conventional three-port } \\
\text { appendicectomy }(n=32)\end{array}$ \\
\hline 1 & Operative time (minutes) & 24 & 42 \\
\hline 2 & Cosmesis & $\begin{array}{l}\text { Two } 5 \text {-mm port scars hidden in umbilicus } \\
\text { and pubic hairline producing "scarless" } \\
\text { appearance }\end{array}$ & $\begin{array}{l}\text { One } 10 \mathrm{~mm} \text { and two } 5 \mathrm{~mm} \text {. Scar } \\
\text { visible at umbilicus and It. iliac fossa }\end{array}$ \\
\hline 3 & Wound infection & $1(0.59 \%)$ & $1(3.125 \%)$ \\
\hline 4 & Hospital stay (mean days) & 1.7 & 2.1 \\
\hline 5 & $\begin{array}{l}\text { Intraoperative rupture of } \\
\text { appendix }\end{array}$ & 0 & 1 (3.125\%) \\
\hline 6 & Intraoperative bleeding & $2(1.19 \%)$ & $2(6.25 \%)$ \\
\hline 7 & Adhesiolysis & 50 & 12 \\
\hline
\end{tabular}


ports in suprapubic region and left iliac fossa. Laparoscopy gives great advantage to both patient and surgeon and also the efforts to reduce the resultant trauma and to increase better cosmetic results by decreasing the size and number of cuts created for the ports. Mini-laparoscopy poses as an option to achieve this by using portals located as usual but with using instruments of smaller diameter. ${ }^{15,16}$ Our technique of mini two-port appendicectomy gives the advantages of the both decreased number and size of the scar as compared to the CLA (Fig. 4).

The TPA technique with loop polypropylene retraction provides a good result even with extensive inflammation, enables stable manipulation, and gives better counter traction than conventional forceps used in three-port technique. The site for placement of the needle loop is decided on the basis of the position of the appendix on laparoscopic visualization of the appendix, also considering ergonomic viewpoint. The umbilical and suprapubic port sites are hidden by natural camouflages, and the left Iliac fossa (LIF) port is the only visible external sign of surgery in the CLA. The two-port technique avoids even this marker of abdominal invasion, ${ }^{17}$ and 5-mm umbilical port further reduces the scar size.

As per Khan and Al-Bassam, ${ }^{18}$ studies suggest that the two-port appendicectomy compared to three port was quicker to perform with less postoperative analgesia requirement with an added advantage of smaller incision and a better cosmetic result. There are many studies that have used this surgical technique ${ }^{19}$ but with use of commercially endoloop, knot pusher.

Our intracorporeal two-port laparoscopic appendicectomy with indigenously completely intracorporeal novel knotting technique is an appealing alternative for the treatment of acute appendicitis because of its decreased invasiveness and improved cosmesis. The use of an intra-abdominal sling technique by using needle retraction suture counterpoises for the lack of the retraction port in the left iliac fossa and eliminates any skin scarring at that site. The use of novel knotting technique helps reduce the size of the working port as 12-mm ports are used in case of stapler-assisted ligation of base of appendix.

In epochs where surgeons are focusing on transluminal approaches to access the abdominal cavity, laparoscopy is favored for its extended advantages of enhanced exposure, ergonomics, instrument diversity, economically sound, and overall patient safety. ${ }^{7}$ TPA is a hybrid technique combines the advantages of laparoscopy, which consists of aspects like improved visualization and better abdominal exploration, and traditional techniques of open surgery. ${ }^{7}$

Nevertheless, despite these advantages, efforts to further decrease the abdominal incision and scar has led into expansion of natural orifice transluminal endoscopic surgery (NOTES). Even though NOTES is virtually scarless as the intra-abdominal entry points are hidden. There are several drawbacks, such as, lack of instruments availability, intraluminal invasion of the hollow organs, and failed sutures, which fails the idea of cost benefit analysis. ${ }^{20,21}$

Single-incision laparoscopic surgery applies a single multiluminal port, or multiple monoluminal ports, through a single skin incision. Although this technique has been embraced by surgeons worldwide, instruments and procedure are under fundamental stage of investigation. ${ }^{22}$ List of disadvantages include lack of triangulation and ease of maneuverability due to clashing of instruments as it uses single umbilical port for all the working instruments and requirements of specialized instruments. As per Donmez et al., ${ }^{23}$ in SILS port procedure, a $2.5-\mathrm{cm}$ incision is required, which may result increased infection risk, port-site hernia, postoperative pain, and subsequently a large visible scar which is avoided in 2-port technique. SILS also demands requirements of specialized instruments leading higher operation cost. ${ }^{24-27}$

The only limitation of TPA with as described by Kiran et al. ${ }^{28}$ is the presence of dense adhesions and long appendix, but here a double retraction technique described in our study can overcome this shortcoming. Our study also describes the technique pragmatic in cases of edematous cecum and grossly inflamed appendix, which further circumvents the likelihoods of conversion to CLA or open appendicectomy. The suture used polyglactin 2-0 in ligating the base of the appendix in our technique is easily available and cost-effective in contrast to the endoloop or Endo Gl stapler. The two-port technique further reducing the financial burden and can be used in rural and peripheral areas with limited resources. ${ }^{29,30}$ This novel suturing technique is easy to learn (reproducible) and apply (replicable), with short learning cure. The overall procedure can be performed by trained laparoscopic surgeon, whereas SILS and NOTES demand expertise and also have a steep learning curve. ${ }^{5}$

In pursuit of minimizing surgical trauma and achieving better esthetics by reducing the size and number of ports, this mini twoport technique is devised to offer an easier and safe alternative in comparison to conventional three-port technique. This led to the invention of laparoscopic surgical knot which can be tied with a single instrument through a single port and single hand which can also be used to ligate cystic duct, renal vessels, splenic vessels, or any other tubular structure without need for additional port.

\section{Conclusion}

This mini two-port technique with novel knotting technique is easy to learn and helps to overcome the challenges and limitations faced during two laparoscopic appendicectomies; however, conversion to conventional approach in complicated cases is still advisable. It is safe and effective intermediate option from conventional three port to SILS/NOTES/Endo GIA staplers.

\section{Statement of Authorship and Conflict of INTEREST}

All authors listed below have participated sufficiently in the work to take public responsibility for appropriate portions of the content.

\section{References}

1. Ramdas MJ, Sing QY, Milne D. Association between the appendix and the fecalith in adults. Can J Surg 2015(1):10-14. DOI: 10.1503/ cjs.002014.

2. Lohar HP, Asger Calcuttawala MA, Nirhale DS, et al. Epidemiological aspects of appendicitis in a rural setup. Med J DY Patil Univ 2014;7(6):753-757. DOI: 10.4103/0975-2870.144867.

3. Patrick DA, Janik JE, Janik JS, et al. Increased CT scan utilization does not improve the diagnostic accuracy of appendicitis in children. J Pediatr Surg 2003;38(5):659-662. DOI: 10.1016/jpsu.2003.5017.

4. Buckius MT, McGrath B, Monk J, et al. Changing epidemiology of acute appendicitis in the United States: study period 1993-2008. J Surg Res 2012;175(2):185-190. DOI: 10.1016/j.jss.2011.07.017.

5. Douglas CD, Macpherson NE, Davidson PM, et al. Randomised controlled trial of ultrasonography in diagnosis of acute appendicitis, incorporating the Alvarado score. Br Med J 2000;321(7266):919. DOI: 10.1136/bmj.321.7266.919.

6. Alvarado A. A practical score for the early diagnosis of acute appendicitis. Ann Emerg Med 1986;15(5):557-564. DOI: 10.1016/ s0196-0644(86)80993-3. 
7. Panait L, Bell RL, Duffy AJ, et al. Two-port laparoscopic appendectomy: minimizing the minimally invasive approach. J Surg Res 2009;153(1):167-171. DOI: 10.1016/j.jss.2008.02.003.

8. Meljnikov I, Radonjic B, Grebe dinger S, et al. History of surgical treatment of appendicitis. Med Pregl 2009;62(9-10):489-492. Serbian.

9. Ali R, Khan MR, Pishori T, et al. Laparoscopic appendectomy for acute appendicitis: is this a feasible option for developing countries? Saudi J Gastroenterol 2010;16(1):25-29. DOI: 10.4103/1319-3767.58764.

10. Aguayo $P$, Alemayehu $H$, Desai AA, et al. Initial experience with same day discharge after laparoscopic appendectomy for nonperforated appendicitis. J Surg Res 2014;190(1):93-97. DOI: 10.1016/j.jss.2014.03.012.

11. Hong TH, You YK, Lee KH. Trans umbilical single port laparoscopic cholecystectomy: scar less cholecystectomy. Surg Endosc 2009;23(6):1393-1397. DOI: 10.1007/s00464-008-0252-y.

12. Lee SE, Choi YS, Kim BG, et al. Single port laparoscopic appendectomy in children using glove port and conventional rigid instruments. Ann Surg Treat Res 2014;86(1):35-38. DOI: 10.4174/astr.2014.86.1.35.

13. Larson GM, Cheadle WG, Polk HC,Jr. Appendectomy for acute appendicitis. In: Ballantyne GH, Leahy PF, Modlin IM. Laparoscopic Surgery. Philadelphia: WB Saunders and Company; 1994. p. 220.

14. Kavic MS. Laparoscopic appendectomy. In: Grochmal S. Minimal Access Gynaecology. Oxford: Radcliffe Medical Press; 1995. p. $149-162$.

15. Lofty M, Khairy MM, Moussa MS. Two-port laparoscopic appendectomy. European J Surg 2017;4:18-22.

16. Yagnik VD, Rathod JB, Phatak AG. A retrospective study of two-port appendectomy and its comparison with open appendectomy and three-port appendectomy. Saudi J Gastroenterol 2010;16(4):268-271. DOI: 10.4103/1319-3767.70611.

17. Two-port vs. three-port laparoscopic appendicectomy: A bridge to least invasive surgery Ashwin Rammohan, Paramaguru Jothishankar, A B Manimaran, and R M Naidu.

18. Khan AR, Al-Bassam A. Two-port versus three-port laparoscopic appendectomy in children with uncomplicated appendicitis. Pead Endosurg Innov Tech 2002;6(4):255-260. DOI: 10.1089/109264102321111565.

19. Olijnyk JG, Pretto GG, da Costa Filho OP, et al. Two-port laparoscopic appendectomy as transition to Laparo endoscopic single site surgery. J Minim Access Surg 2014;10(1):23-26. DOI: 10.4103/0972-9941. 124460.
20. Sauerland S, Lefering R, Neugebauer EA. Laparoscopic versus open surgery for suspected appendicitis. Cochrane Database Syst Rev 2004(4):CD001546. DOI: 10.1002/14651858.CD001546.pub2.

21. Neugebauer EAM, Sauerland S, Fingerhut A, et al. EAES guidelines for endoscopic surgery: twelve years evidence-based surgery in Europe. Berlin: Springer; 2006. pp. 345-346.

22. Li P, Chen Z-H, Li Q-G, et al. Safety and efficacy of single-incision laparoscopic surgery for appendectomies: a meta-analysis. World Journal of Gastroenterology: WJG 2013;19(25):4072-4082. DOI: 10.3748/wjg.v19.i25.4072.

23. Donmez T, Hut A, Avaroglu H, et al. Two-port laparoscopic appendectomy assisted with needle grasper comparison with conventional laparoscopic appendectomy. Ann Surg Treat Res 2016;91(2):59-65. DOI: 10.4174/astr.2016.91.2.59.

24. Lee J, Baek J, Kim W. Laparoscopic trans umbilical single-port appendectomy: initial experience and comparison with three-port appendectomy. Surg Laparo Endosc Percutan Tech 2010;20(2):100103. DOI: 10.1097/SLE.0b013e3181d84922.

25. Lee YS, Kim JH, Moon EJ, et al. Comparative study on surgical outcomes and operative costs of trans umbilical single-port laparoscopic appendectomy versus conventional laparoscopic appendectomy in adult patients. Surg Laparo Endosc Percutan Tech 2009;19(6):493-496. DOI: 10.1097/SLE.0b013e3181c15493.

26. St Peter SD, Adibe OO, Juang D, et al. Single incision versus standard 3-port laparoscopic appendectomy: a prospective randomized trial. Ann Surg 2011;254(4):586-590. DOI: 10.1097/SLA.0b013e31823003b5.

27. Park JH, Hyun $\mathrm{KH}$, Park $\mathrm{CH}$, et al. Laparoscopic vs trans umbilical single-port laparoscopic appendectomy; results of prospective randomized trial. J Korean Surg Soc 2010;78(4):213-218. DOI: 10.4174/ jkss.2010.78.4.213.

28. IOSR Journal of Dental and Medical Sciences www.iosrjournals.org 10.9790/0853-14382124 www.iosrjournals.org 21 | Page Needle Port Assisted Two-Port Laparoscopic Appendicectomy Kiran Kumar KM, Naveen Kumar M, Srinivas Arava, Kishore Krishna, Pratheek KC.

29. Chamberlain RS, Sakpal SV. A comprehensive review of singleincision laparoscopic surgery (SILS) and natural orifice transluminal endoscopic surgery (NOTES) technique for cholecystectomy. J Gastrointestinal Surg 2009;13(9):1733-1740. DOI: 10.1007/s11605-0090902-y.

30. Romanelli JR, Earle DB. Single-port laparoscopic surgery: an overview. Surg Endosc 2009;23(7):1419-1427. DOI: 10.1007/s00464-009-0463-x. 